people". The proposal has been cordially received in Ireland, and now has the official approval of the President of the Irish Free State. The archæological section of the expedition is already at work and during the past summer, under the leadership of Dr. O'Neil Hencken and under the auspices of the National Museum of Ireland, has been engaged in the excavation of a Viking age crannog at Ballinderry, Co. Westmeath, and of bronze age burials nearby at Knockast, with remarkable results. For the study of social anthropology, Co. Clare has been chosen as the area affording most typically a blend of the old and the new in Irish culture. A preliminary survey has been made by Prof. W. Lloyd Warner, assistant professor of social anthropology in Harvard University, assisted by Mr. Conrad Arensburg, postgraduate anthropological student of the University. It is intended to devote two years with an extended staff to the observation of every aspect of Irish social life. Physical anthropology will be under the charge of Prof. E. A. Hooton, of Harvard University, who will also be responsible for the general oversight of the work of the expedition.

\section{Excavation in Alaska}

DuRING the past summer an expedition of the University Museum of Pennsylvania, conducted by Miss Frederika de Laguna, has been at work on the coasts of Alaska in conformity with the policy of American anthropology for the intensive study of this area in relation to the problem of the early peopling of America. The expedition was engaged in the excavation of a prehistoric village site in Kachemak Bay, Cook Inlet. Of the finds of the season, Science Service (Washington D.C.) reports that Miss de Laguna regards the outstanding object to be a carved stone lamp. In the bowl of the lamp is a human figure in an attitude of prayer carved in full relief. Four other examples of such lamps are known; but this is the only example to be found by a scientific explorer in situ. It is said to come from the last phase of four prehistoric Eskimo settlements; but although the early phase of the 'archaic' culture of the area is remarkable for its carved ivories, stone carving is not known as an Eskimo technique. The lamp was found in a shell-heap close to the sea, which is washed by high tide. Other cultural features of the same settlement were slate mirrors, slate blades for lances, bone harpoons and dart heads, grinding stones, awls, drills, dolls, beads and needles. Rock-paintings were found in caves. Such paintings are known only in southern Cook Inlet and on Kodiak Island, where the culture is similar. The Indians of to-day believe that these pictures were painted by 'whale killers', much feared medicinemen who poisoned their lances with human fat. If there were any foundation for this belief, it might be related to the traces of cannibalism found in prehistoric settlements by the Smithsonian Alaskan expeditions.

\section{Spelling of Place Names}

The United States Geographic Board has published a "First Report on Foreign Geographical
Names" (Washington Government Printing Office, 1932. 10 cents). The list of names is prefaced by a long discussion of the problems involved, which is followed by certain general rules that the Board has adopted. The conventional English usage is adopted for the names of countries, dominions, colonies, etc., and for geographical features common to several States in which the official languages are different. For local geographical names in States where a Latin alphabet is used, the names are spelled in accordance with local usage but conventional English forms, where such exist, are accepted as alternatives. Names in non-Latin alphabets are to be transliterated according to either official transliteration, where such exists, or a system adopted by the Board and printed in this report. The practice of translating names is discouraged. The policy adopted by the Board differs little from that used by the Permanent Committee on Geographical Names for British Official Use. The differences lie in the spelling of names in possessions of European powers and in the transliteration of ' $\mathrm{j}$ ' and ' $\mathrm{zh}$ ' in certain languages, but it is laid down that in the absence of any specific decision of the United States Board, the decision of the British Committee is to be followed in certain cases. The actual list of names in the Report gives pronunciation in many cases but omits it in several names where its addition would certainly be useful.

\section{Forest Fires in Japan}

A PAPER on "Forest Fires and Weather" (Sci. Papers Inst. Phys. Chem. Res., Tokyo, vol. 18), by T. Terada and T. Utigasaki, states that the annual loss due to forest fires in Japan is second in magnitude only to that suffered by the United States. Japanese meteorologists might therefore do good service by studying the weather conditions that precede these fires in Japan, and perhaps eventually organising a system of warnings, following the example of the United States. The authors of this paper were led to study this subject with the aid of synoptic weather charts through the known tendency for the fires to break out practically simultaneously in widely scattered parts of Japan. They conclude that such outbreaks are generally associated with the near approach of the 'squall-line' or principal cold front of a depression following an easterly track north of Japan, when the warmer of the two wind currents yields maximum temperatures of $20^{\circ} \mathrm{C}$. or more. There seems no a priori reason why the front should have anything to do with the matter; it is easy to imagine that the necessary antecedent conditions are merely a sufficiency of wind and warmth, with no rain and perhaps some special state of the air in regard to its water-vapour content. These conditions might seldom occur except on the approach of a depression. As frequently happens with investigations in which synoptic charts are used, the extent to which the evidence supports the conclusions cannot be gauged accurately unless all the charts are reproduced in great detail. It must have been difficult for the authors to determine the position of the front in 
relation to the outbreaks, seeing that they had to rely upon newspaper reports for the times of the outbreaks.

\section{The Disturbing Influence of Science}

LECTURING to the Science Federation of the University of Manchester on January 23 under the title "The Irresponsibility of Science", Prof. H. Levy asserted that the problems of unemployment and the distribution of leisure are problems which the man of science must help to solve. It is part of the duty of the scientific man to examine the external properties of science and to face the ethical problems which the application of scientific discoveries is liable to create. The habit engendered in the scientific worker by his very method of endeavouring to isolate objects or causes and consider the influence of single factors in a problem has a very real danger in that it leads scientific workers to assume that all scientific questions are independent of ethics. Practically all scientific work, however, has a social aspect and its social properties cannot be clearly separated from its scientific properties any more than theoretical and applied science can be sharply demarcated. At the present time we are being forced to consider indeed the limit beyond which the process of improving the weapons of production is likely to disturb the structure of the original scientific movement itself. The scientific worker cannot ignore the fact that in practice what is intended as a gift of more leisure for all becomes unemployment and loss of consuming power for some. Scientific men must endeavour to find what factors go to the creation of an unstable society under the impact of science in this way. Prof. Levy suggested that scientific men should analyse the tendencies of science so that they could direct them. Science, which has been a revolutionary factor, has now become a disturbing factor in the world, affecting the stability of communities, and the study of that disturbance is one for international science.

\section{Science and the Textile Industry}

Speaking on January 26 on the textile industry in the course of lectures on industrial affairs which are being given to the students of the Imperial Coilege of Science and Technology, Dr. Kenneth Lee expressed his belief that the rapid development of scientific research will prove the best investment the textile industry can make. The British Cotton Industry Research Association has undoubtedly the best equipped textile research institute in the world, but although about eighty per cent of those engaged in production contributed to it, in relation to the magnitude of the industry the amount subscribed is negligible. Dr. Kenneth Lee believes that if the necessary financial support is forthcoming, we could dominate to a large extent the cotton textile field in the production of new inventions during the next few years. In addition to utilising science, the cotton industry must also employ men in its mills who can understand the work that science is doing. Dr. Kenneth Lee referred in particular to the way in which science, by introducing means of artificial humidification and ventilation, has not only discounted what was once supposed to be a great advantage of the Lancashire industry-its damp climate-but has made it possible to obtain uniform conditions throughout the year with higher output and more efficient use of automatic machinery.

\section{Direct-Current Generators for Electrostatic Precipitation}

IN the English Electric Co.'s Journal for October, a description is given of the high-pressure D.C. dynamos it constructs for use in electrostatic precipitation plant. The Whessoe Foundry and Engineering Co., Ltd., specialises in apparatus for fog and mist extraction, and the English Electric Co.'s dynamos are specially designed to work with its plant. The removal of suspended particles from large volumes of gas is an important commercial problem at the present time. Electrostatic precipitation is now regarded as the most efficient and economical method for cleaning gases. The English Electric Co. has designed many high-pressure D.c. machines for radio transmission purposes, and the new dynamos are based on the experience gained in radio work. The generating unit for a typical equipment has to supply a current of about $0 \cdot 15$ amperes at a pressure of 45 kilovolts. The unit consists of a driving motor made to suit the local supply, coupled to three generators connected in series. The frames of the machines are insulated from the earth by individual supports of solid porcelain. The whole of the high-pressure apparatus is enclosed by screens which separate it from the driving motor and prevent unauthorised access. A simple interlock on the door renders it impossible for anyone to enter the high-pressure compartment when the generators are running. As a further precaution, every conductor which is at high pressure when the machine is running is connected with the earth when the set is at 'standstill'. Accidental shocks are thus avoided. A notable feature of the set is its ability to withstand a short circuit without a 'flash-over'. A model precipitation equipment was shown in action at the English Electric Co.'s exhibition last November.

\section{Ship Researches at the William Froude Laboratory}

Durrng the last ten or twelve years, no fewer than twenty-two papers have been contributed to the transactions of the Institution of Naval Architects, the North-East Coast Institution of Engineers and Shipbuilders and other bodies, by the members of the staff of the William Froude Laboratory, National Physical Laboratory, Teddington. Among these papers are six on the effect of weather conditions on the propulsion of ships, seven on the manœuvring of ships and six on the efficiency of screw propellers. The other papers deal with the hulls of flying boats and ship propulsion data. Needless to say, all the papers are of permanent value and they have now been re-issued as vol. 23 of the Collected Researches of the National Physical Laboratory (London : H.M. Stationery Office. 20s. net). Arrangements have also been made to publish them in five groups. Each 